\title{
Article
}

\section{food safety and the hygiene misnomer}

\author{
Wallace, Carol Anne \\ Available at http://clok.uclan.ac.uk/16175/ \\ Wallace, Carol Anne ORCID: 0000-0002-1402-2134 (2016) food safety and the \\ hygiene misnomer. Perspectives in Public Health, 136 (4). pp. 197-198. ISSN \\ $1757-9139$
}

It is advisable to refer to the publisher's version if you intend to cite from the work.

For more information about UCLan's research in this area go to

http://www.uclan.ac.uk/researchgroups/ and search for < name of research Group>.

For information about Research generally at UCLan please go to http://www.uclan.ac.uk/research/

All outputs in CLoK are protected by Intellectual Property Rights law, including Copyright law. Copyright, IPR and Moral Rights for the works on this site are retained by the individual authors and/or other copyright owners. Terms and conditions for use of this material are defined in the policies page.

\section{CLoK}

Central Lancashire online Knowledge www.clok.uclan.ac.uk

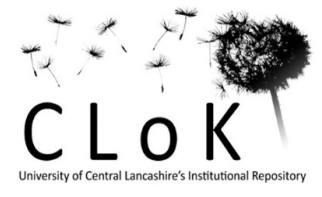




\section{Food safety and the hygiene misnomer}

Prof. Carol A. Wallace, Professor of Food Safety Management Systems and Co-Director, Institute of Nutritional Sciences and Applied Food Safety Studies, School of Sport and Wellbeing, University of Central Lancashire

From a food safety perspective, effective standards of hygiene and cleanliness throughout the food chain are understood to be key factors in reducing the incidence of foodborne disease. Therefore, it is difficult to postulate that we could ever be too clean from the point of view of controlling microbiological hazards in foods. Whist interactions within the human biome are highly complex and many pathways remain to be understood, it is important that views that we might be 'too clean' are not allowed to overrule application of food hygiene practices either in the food industry or in the home.

\section{The burden of foodborne illness}

Foodborne illness is a significant burden globally. Recently published data from the World Health Organisation (WHO) estimate the burden of foodborne diseases in 2010 to be 600 million foodborne illnesses (95\% uncertainty interval [UI] 420-960 million) and 420,000 deaths ( $95 \%$ UI 310,000$600,000)$ due to 31 global hazards. ${ }^{1}$ The most frequent causes were foodborne diarrhoeal disease agents, which caused 230,000 deaths (95\% UI 160,000-320,000), and the most common agents involved in diarrhoeal disease were norovirus and Campylobacter, with deaths particularly associated with non-typhoidal Salmonella enterica, Salmonella Typhi, Taenia solium, hepatitis A virus and aflatoxin. ${ }^{1}$ Forty percent of the burden was in children under the age of 5 years old and, as might be expected, there was considerable variation across regions of the world. ${ }^{1}$

Whilst it is clear that a large proportion of the burden lies in developing countries ${ }^{1}$, foodborne illness affects the food industry and consumers all over the world ${ }^{2}$ with previous estimates reporting that in industrialised countries up to $30 \%$ of the population may be affected each year. ${ }^{3}$ In the UK around a million people suffer foodborne illness every year, and this includes 20,000 people who need hospital treatment, and approximately 500 deaths. ${ }^{4}$ This costs the UK economy close to $f 1.5$ billion each year ${ }^{4}$ whereas recent annual cost estimates in the USA are at $\$ 77.7$ billion $(90 \% \mathrm{Cl}, \$ 28.6$ to $\$ 144.6$ billion). ${ }^{5}$ Clearly, foodborne disease remains an important problem to be overcome in both developed and developing countries.

\section{Responsibilities and Problems in the food supply chain}

Although the above figures may seem alarming, our food supply in the developed world has probably never been safer ${ }^{6}$; however, data suggest that there are still weaknesses in the way that food safety is managed within the food supply chain, even in some larger food businesses. ${ }^{7}$

HACCP-based Food Safety Management Systems have long been accepted as the mechanisms that food companies should use to protect the consumer by controlling and preventing the potential presence of food safety hazards. ${ }^{8}$ HACCP systems do not work in isolation but in combination with prerequisite hygiene programmes and management practices within the overall food safety culture. ${ }^{8}$ All of these elements are important however it can be a complex balancing act to ensure that all the necessary systems and procedures are working together at all times and that staff and management personnel are all playing their parts effectively.

Looking at the causes of foodborne disease outbreaks, cross contamination and poor hygiene standards have been identified as key causes of foodborne illness. It is therefore somewhat 
worrying to read recent summary data, published by one of the largest $3^{\text {rd }}$ party food safety audit bodies, reporting on trends in audits across more than 17,000 food chain sites; this clearly identifies the most common non-conformities are occurring in areas such as housekeeping and hygiene (including cleaning systems), product contamination control, building fabric and equipment. ${ }^{9}$ Considering the importance of prerequisite programmes in supporting HACCP has been understood for many years ${ }^{10}$ it is disappointing to note that these key hygiene foundations are being overlooked, at least by some food companies. It is not clear whether the weaknesses are related to systems and resources, lack of understanding and/or cultural or people systems factors. However, these data suggest that the role of hygiene practices as the 'first line of defence ${ }^{11}$ against foodborne disease needs to be further promoted in the food supply chain and that more time and effort needs to be directed to getting basic hygiene standards correct.

\section{The importance of the Consumer}

Consumer perception of food safety continues to be problematic; consumers expect that food is intrinsically safe and their perception of risk differs from that of experts. ${ }^{6}$ Public health campaigns regularly aim to provide consumers with information about food safety risk and necessary controls, including hygiene practices, but most consumers do not worry about safety in their normal day to day lives. ${ }^{6}$ Food safety is often not a priority in domestic kitchen life but outbreaks of foodborne illness are known to occur in the home and understanding of real life kitchen practices is important in targeting food safety interventions. ${ }^{12}$

Cleaning and hygiene practices in the domestic setting are important tools in reducing food cross contamination but the understanding of different groups of consumers may vary and this may limit effectiveness. For example, historical learned wisdom in the UK often led to the washing of poultry before cooking as part of home preparation; however, this is known to spread harmful microorganisms such as Salmonella and Campylobacter around the kitchen and onto other foodstuffs. Therefore, recent campaigns from the UK Food Standards Agency have been focused on not washing poultry, e.g. the 'Don't Wash Raw Chicken' Campaign. ${ }^{13}$ Other concerns about washing and cross-contamination come from the produce industry, where it has been demonstrated that washing can move bacteria from salad leaves to wash water which, in turn, can contaminate previously uncontaminated leaves. ${ }^{14}$ These messages have potential to cause confusion about washing and cleaning practices in domestic kitchens and there is a need for better guidance on what to wash and how.

\section{Conclusions}

Food safety management is a complex topic. In the food supply chain, it requires application of systems and procedures, such as HACCP, prerequisite (hygiene) programmes and effective management practices, all operating within a positive food safety culture; in the home it requires application of hygienic practices to prevent the spread of contamination, as well as washing of some food items to reduce surface contamination and effective cooking and storage procedures to prevent microbial survival and proliferation. With the number of elements that have to be correctly applied, both in the food supply chain and the home, it is perhaps not surprising that foodborne disease outbreaks occur from time to time. However, from a food safety perspective, the 
importance of cleaning and hygiene will remain a cornerstone of health protection. It would be extremely unwise to suggest that we can be too clean for food safety.

\section{References}

1. World Health Organisation. WHO Estimates of the Global Burden of Foodborne Diseases. Foodborne Disease Burden Epidemiology Reference Group 2007-2015. World Health Organisation, 2015. ISBN 978924156516 5. Available online at: http://apps.who.int/iris/bitstream/10665/199350/1/9789241565165 eng.pdf?ua=1 (Last accessed $11^{\text {th }}$ April 2016).

2. DeWaal, C.S., Robert, N., Witmer, J., and Tian, X.A., A comparison of the burden of Foodborne and Waterborne Diseases in Tree World Regions, 2008. Food Protection Trends, 2010, Vol. 30, No. 8, Pages 483-490.

3. WHO (2002), Food safety and foodborne illness, Factsheet, No. 237, World Health Organization, Geneva, (Last accessed October 2004; now superseded).

4. Food Standards Agency. Foodborne Disease Strategy 2010-2015, an FSA Programme for the Reduction of Foodborne Disease in the UK. Food Stadards Agnecy, 2011, Available online at: http://www.food.gov.uk/sites/default/files/multimedia/pdfs/fds2015.pdf (Last accessed 11th April 2016).

5. Scharff, R.L., Economic Burden from Health Losses Due to Foodborne Illness in the United States, Journal of Food Protection, Vol. 75, No. 1, 2012, Pages 123-131.

6. Verbeke, W., Frewer, L. J., Scholderer, J. and De Brabander, H. F., 2007, Why consumers behave as they do with respect to food safety and risk information, Analytica Chimica Acta 586 (2007) 2-7

7. Powell, D.A., Jacob, C.J. and Chapman, B., 2011, Enhancing food safety culture to reduce rates of foodborne illness, Food Control, 22, 817-822.

8. Wallace, C. A., 2014, HACCP-based food safety management systems: great in theory but can we really make them work in practice?, Guest Editorial, Perspectives in Public Health July 2014 134: 188-190.

9. British Retail Consortium (BRC), 2015, Food Safety - a Global View, http://www.brcglobalstandards.com/Portals/0/library/files/knowledgecentre/Food\%20Safet y\%20-\%20A\%20Global\%20View\%202015.pdf (Last Accessed 13 ${ }^{\text {th }}$ April 2016).

10. Wallace, C.A. \& Williams, A.P., 2001, Pre-requisites - a Help or a Hindrance to HACCP, Food Control, 12 (4).

11. Wallace, C. A., Manning, L. and Soon, J. M., 2016, Foodborne Disease Outbreaks: Lessons Learned, in Soon, J.M., Manning, L. and Wallace, C.A., Foodborne Diseases - Case Studies of 
Outbreaks in the Agri-Food Industries, Boca Raton, CRC Press.

12. Wills, W>J>, Meah, A., Dickinson, A.M. and Short, F., 2015, 'I don't think I ever had food poisoning'. A practice-based approach to understanding foodborne disease that originates in the home., Appetite, 85, 118-125.

13. Food Standards Agency, 2014, Don't Wash Raw Chicken, https://www.food.gov.uk/sites/default/files/multimedia/pdfs/publication/dont-wash-rawchicken-leaflet.pdf (Last Accessed $14^{\text {th }}$ April 2016)

14. Jensen, D.A., Friedrich, L.M., Harris, L.J., Danyluk, M.D. and Schaffner, D.W., 2015, Cross contamination of Escherichia coli $0157: \mathrm{H} 7$ between lettuce and wash water during homescale washing, Food Microbiology, 46, 428-433. 